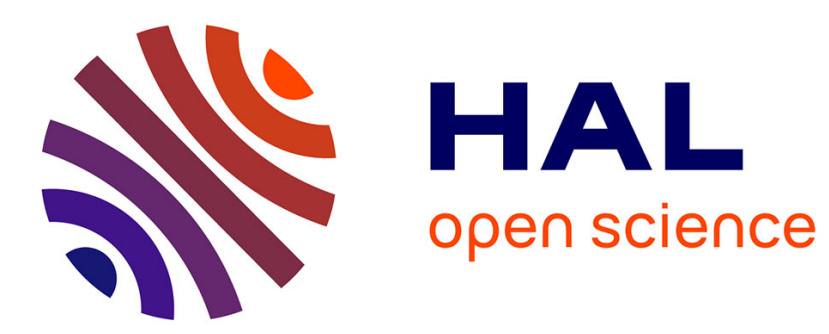

\title{
A single-center series of 482 patients with functional motor disorders
}

\author{
Béatrice Garcin, Nicolas Villain, Francine Mesrati, Lionel Naccache, \\ Emmanuel Roze, Bertrand Degos
}

\section{To cite this version:}

Béatrice Garcin, Nicolas Villain, Francine Mesrati, Lionel Naccache, Emmanuel Roze, et al.. A singlecenter series of 482 patients with functional motor disorders. Journal of Psychosomatic Research, 2021, 148, pp.110565. 10.1016/j.jpsychores.2021.110565 . hal-03287987

\section{HAL Id: hal-03287987 \\ https://hal.sorbonne-universite.fr/hal-03287987}

Submitted on 16 Jul 2021

HAL is a multi-disciplinary open access archive for the deposit and dissemination of scientific research documents, whether they are published or not. The documents may come from teaching and research institutions in France or abroad, or from public or private research centers.
L'archive ouverte pluridisciplinaire HAL, est destinée au dépôt et à la diffusion de documents scientifiques de niveau recherche, publiés ou non, émanant des établissements d'enseignement et de recherche français ou étrangers, des laboratoires publics ou privés. 


\section{A single-center series of $\mathbf{4 8 2}$ patients with functional motor disorders}

Béatrice Garcin (1,2); Nicolas Villain (2,3); Francine Mesrati (4); Lionel Naccache (4); Emmanuel Roze (2,3); Bertrand Degos (1,5);

(1) Service de Neurologie, Hôpital Avicenne, Hôpitaux Universitaires de Paris - Seine Saint Denis, Sorbonne Paris Nord, AP-HP, Bobigny, France

(2) Sorbonne Université, Institut du Cerveau - Paris Brain Institute - ICM, Inserm, CNRS, Paris, France

(3) Département de Neurologie, Groupe Hospitalier Universitaire Pitié-Salpêtrière, Paris;

(4) Service de Neurophysiologie, Groupe Hospitalier Universitaire Pitié-Salpêtrière, Paris;

(5) Dynamics and Pathophysiology of Neuronal Networks Team, Center for Interdisciplinary Research in Biology, Collège de France, CNRS UMR7241/INSERM U1050, Université PSL, 75005 Paris, France

\section{Corresponding author:}

Béatrice Garcin,

Service de Neurologie, Hôpital Avicenne, 125 route de Stalingrad, 93000 Bobigny, France;

Telephone: 0148955401, email: béatrice.garcin@aphp.fr

Word count: 2397

Highlights:

- We report 482 patients with functional motor disorders, median age was 40 years old

- Half had weakness and half had movement disorders, mainly tremor and dystonia

- No difference was found in age or gender regarding the clinical phenotype.

- $\quad 58 \%$ of the patients were unemployed because of the functional movement disorder.

Keywords:

- Functional motor disorders

- Functional movement disorders

- Psychogenic movement disorders

- Clinical phenotypes

- Unemployment 


\begin{abstract}
Functional motor disorders (FMD) are common and disabling. They are known to predominantly affect women and young to middle-aged patients, although they also occur during childhood or in the elderly. Demographic and clinical characteristics of patients with FMD are poorly known, since large series of consecutive patients are scarce.

Methods: In a chart review study, we retrospectively abstracted data from consecutive FMD patients who were referred to the Neurophysiology Department of the Salpêtrière University Hospital between 2008 and 2016 for treatment with repeated transcranial magnetic stimulation.

Results: 482 patients were included. Most patients were women (73.7\%). Median age at symptoms onset was 35.5 years and symptoms were mostly characterized by acute $(47.3 \%)$ or subacute $(46 \%)$ onset. Only $23 \%$ of patients were active workers, while $58.3 \%$ were unemployed because of FMD. Half of the patients had functional motor weakness $(n=241)$ whereas the other half had movement disorders $(n=241)$, mainly with tremor $(21.1 \%)$ or dystonia (20.5\%). Among all patients, $66.4 \%$ had psychiatric comorbidity and $82.6 \%$ reported a history of trauma in the 6 months before symptoms onset. No difference was found in age or gender according to clinical phenotypes.
\end{abstract}

Conclusion: This large series will contribute to better characterize FMDs. 


\section{Introduction}

Functional Neurological Disorders (FND)s are the second commonest reason for referral in Neurology outpatient clinics [1]. FND can affect motor and/or sensory functions, other senses, cognition, and can also manifest as non-epileptic seizures. The current understanding of the disease involves brain network dysfunction that is potentially reversible, individual vulnerability and the possibility of an emotional/psychological trigger [2,3]. Functional motor disorder (FMD) is a common presentation of FND. Patients with FMD can present with a variable combination of weakness, tremor, jerks, stereotypies, dystonia and parkinsonism. FMD is more frequent in women and often start at young to middle age [4-9], although they can also occur in childhood or in the elderly $[10,11]$. There are still controversies regarding the increased prevalence of psychiatric comorbidities in FMD. For example, some authors found more depression and/or anxiety disorders in FMD patients than in "organic" patients $[6,9]$, but other did not $[15,16]$. Recent studies have suggested that some phenotypes predominantly affect one gender or one age group. For example, previous studies suggested that functional myoclonus is more frequently observed in men (55\%)[12], while functional parkinsonism is more frequent in older patients [13]. Some discrepancies also exist about FMD predominantly affecting the left side of the body [14]. Large case series are rare and there is a need to characterize in details this patient population. Additionally, this patient population mostly comprises young or middle-aged adults who potentially are active workers, but their work statuses are poorly known.

In the present study, we aimed at describing the demographic and clinical characteristics of a consecutive series of FMD patients, including the repercussions of FMD on their work status. We will also assess whether the characteristics of the patients vary depending on the phenomenology.

\section{Material \& Methods}

\section{$\underline{\text { Population }}$}

We retrospectively abstracted demographic and clinical data of consecutive patients referred to the Neurophysiology Department of the Salpêtrière University Hospital for functional motor disorders (FMD) over an 8 years period. All patients were referred for transcranial magnetic stimulation (TMS) as a treatment of FMD [17]. A thorough clinical investigation in 
the Movement Disorder Unit of the Salpêtrière University Hospital was performed for all patients. The diagnosis of functional motor weakness was made by a movement disorders' expert according to the criteria for clinically established functional movement disorders [18], after comprehensive investigations including brain imaging and sensory and motor evoked potentials. The data abstraction was approved by the local ethics committee (CPP IdF 6, PitiéSalpêtrière University Hospital) and a form was fulfilled for the National Commission on Informatics and Liberty (CNIL). According to the French law regarding clinical retrospective studies, a written consent of patients was not mandatory but patients were informed that their health data could be anonymously used for retrospective research. No patients objected to this.

\section{Data abstraction}

We performed a chart review study. Clinical and demographic data were abstracted from patients' medical records and completed by a systematic medical interview before neurophysiology assessment and TMS treatment. Patients were asked about comorbidities during a simple interview. All interviews were performed by one clinician (FM), who asked questions about somatic comorbidities looking for any other diseases and other medical history, and also questions about psychiatric history such as anxiety and/or depression and possible visits to the psychiatrist. Further interviewing was dependent on patients' responses to these first questions.

Age at symptoms onset, age at TMS treatment, gender, education level, medical history and psychiatric comorbidities were abstracted.

The onset of symptoms was defined as follows: sudden if the patient reported a sudden onset of symptoms at a precise moment, subacute if symptoms had settled progressively across several weeks to 3 months, chronic if symptoms appeared progressively upon more than 3 months. History of trauma was either spontaneously reported by the patient or reported during the medical interview. An systematicinterview was performed in search of potential triggering factors. Patients were asked about potential physical and psychological trauma that occurred in the 6 months preceding symptoms onset. A psychotrauma was defined as a painful memory of an unexpected event that was reported to be traumatic by the patient (e.g. psychological harassment, death of a relative, diagnosis announcement...). A physical trauma was defined as a painful memory of a physical integrity violation reported as being traumatic by the patient (e.g. accident, surgery...), with or without physical sequelae. The occupational status 
was defined as active if the patient was working or active in another way (e.g.: studies); the absence of activity was then either classified as being unemployed due to non-medical reasons (e.g. unemployment, retirement...) or as being unemployed due to medical reasons (injury-on-duty leave, sick leave, disability living allowance).

Movement disorder phenomenology was classified by a movement disorder expert. In case of multiple functional symptoms, the main symptom was used for classification. Location of symptoms was also reported.

\section{$\underline{\text { Statistical analyses }}$}

Statistical analyses were conducted using SPSS software version 23 (http://www01.ibm.com/software/analytics/spss/), with a threshold set at $\mathrm{p}<0.05$ for significance. Data were first reported for the whole group of patients. Then, we compared the characteristics of patients with the following motor phenotypes: functional motor weakness versus movement disorders and then across different movement disorders subtypes.using. Parametric tests were used for comparison of quantitative variables across groups, following the Central Limit Theorem. Student t-tests were used for comparison of two groups. Analyses of variance (ANOVAs) were used to compare more than two groups, dependent variable was the quantitative data and independent variable was the patients' group (e.g.: type of motor disorder). $\mathrm{Chi}^{2}$ tests were used for comparison of qualitative variables across groups. Data are expressed as median (range) and/or mean \pm standard deviation (SD) and percentage.

\section{Results}

\section{Whole patients group}

Over an 8 years period, 485 patients were referred to the Neurophysiology Department of the Pitié-Salpêtrière University Hospital for TMS treatment of FMD. All the patients were included in the present study except for 3 patients, who were excluded because the motor and sensory evoked potentials were abnormal, leading to diagnosis reappraisal. Demographic and clinical characteristics of patients are described in Table 1 and supplementary Figure 1. There was a majority of women (73.7\%) with a median age of 40 years old (range 8-77) at TMS treatment. Median age at symptoms onset was 35.5 years old (range 3-75) and symptoms were mostly characterized by an acute $(47.3 \%)$ or subacute $(46.1 \%)$ onset. Median duration of symptoms was 23.9 months (range 0-786) - see supplementary Figure 2. Only 23.0\% of patients were active workers while $58.3 \%$ were unemployed for medical reasons, due to FMD 
in all cases. Regarding the phenomenology, half of the patients suffered from functional motor weakness $(n=241)$ and the other half suffered from movement disorders $(n=241)$, mainly with tremor $(21.2 \%)$ or dystonia $(20.5 \%)$. The other movement disorders were jerks (4.6\%), stereotypies (1.9\%) and parkinsonism (1.9\%). Amongst our patients, $18.8 \%$ had a medical history of other neurological disorders, $24.7 \%$ of orthopaedic-rheumatological disorders, complex regional pain syndrome or fibromyalgia, and $13.3 \%$ had a history of abdominal or pelvic disorder. About half of the patients $(47.3 \%)$ had no somatic medical history. Regarding psychiatric comorbidities, $52.7 \%$ of patients suffered from mood disorders (depression in 49.3\% and bipolar disorder in 3.3\%) and 33.6\% had no psychiatric comorbidity. Finally, regarding potential triggering factors, $50.6 \%$ of the patients reported a history of psychological trauma, $20.1 \%$ a physical trauma without sequelae and $8.7 \%$ surgical procedures, while $17.4 \%$ reported no history of trauma in the 6 months before symptoms onset.

\section{Comparisons between groups (see Table 2 and supplementary Table 1):}

Comparisons between functional motor weakness patients and functional movement disorders patients

Patients with functional motor weakness were significantly younger at TMS treatment than patients with functional movement disorders $(\mathrm{t}=-3.75, \mathrm{p}<0.001)$. However, disease duration before TMS treatment was shorter in patients with functional motor weakness $(\mathrm{t}=-6.01$, $\mathrm{p}<0.001$ ), and there was no difference between both groups regarding age at symptoms onset $(\mathrm{t}=-1.077, \mathrm{p}=0.28)$. There was no difference between the two groups in terms of education level, occupation, medical somatic history, psychiatric comorbidities, self-reported trauma history or symptoms onset (see Table 2).

Comparisons between functional movement disorders' phenotypes (see supplementary Table 2)

There was no difference in term of age at TMS, age at symptoms onset, disease duration, sex ratio, educational level, occupation, medical somatic history, psychiatric comorbidities, selfreported trauma history or symptoms installation between the 5 phenotypes of functional movement disorders. Nonetheless, patients with parkinsonism tended to be older at disease onset $(\mathrm{F}=1.47 ; \mathrm{p}=0.21)$. Likewise, patients with dystonia and tremor tended to have larger symptoms duration than patients with parkinsonism, jerks and stereotypies $(F=1.43 ; p=0.22)$. 


\section{$\underline{\text { Location of symptoms }}$}

Location of symptoms is detailed in Table 3 and supplementary Table 3. In both functional movement disorders and motor weakness, bilateral symptoms were predominant. Overall, symptoms were bilateral in 249 (51.7\%), left sided in 136 (28.2\%), and right sided in 97 (20.1\%). However, symptoms were more likely to be bilateral in functional movement disorders (movement disorder: $n=133 / 241$ (55.2\%); weakness: $n=116 / 241$ (48.1\%)), and more likely to be only left-sided in weakness (movement disorder: $n=53 / 241$ (22.0\%); weakness: $\mathrm{n}=83 / 241(34.4 \%)) ;\left(\chi^{2}=9.52 ; \mathrm{p}=0.009\right)$. Additionally, statistics $\left(\chi^{2}=125.7 ; \mathrm{p}<0.001\right)$ revealed a higher proportion of left-sided symptoms for the lower limbs and a right-sided predominance of symptoms for upper limbs amongst patients with functional motor weakness and dystonia (with dystonia being more often monomelic regarding the lower limbs and targeting especially the head and neck compared to the motor weakness group). Tremor, parkinsonism and jerks symptoms were mainly bilateral. Finally, lower limbs symptoms were predominant only in patients with functional motor weakness $\left(\chi^{2}=89.50 ; p<0.001\right)$.

\section{Discussion:}

We describe a series of 482 consecutive patients with functional motor disorder, with a median age of 40 years old. Half of the patients had functional motor weakness and the other half had movement disorders, mainly tremor or dystonia. No difference was found in age or gender regarding the clinical phenotype. Most patients were unemployed for medical reasons. This finding points to the huge socio-economical burden of FMD and emphasizes the need for better diagnostic procedure and active management.

Our study has some limitations. Enrollment was carried out in a tertiary referral center for Neurology, which may lead to a selection bias, in the absence of a control group for comparison. Extreme ages were under-represented, since we did not include children and older patients who are usually referred in pediatric and geriatric units, respectively. However, we report here 482 consecutive patients from one center. Other large series of FMD patients included 410 in an Italian multicenter sample of consecutive patients [5], 196 consecutive patients from a single center in the USA [4], and 160 non consecutive patients from a multicenter trial on online education in the Netherlands [19]. Most comorbidities were assessed via clinical records or patient interviews. Most comorbidities were assessed via clinical records or patient interviews, without systematic questionnaires. Hence, the frequency of psychological stressors and comorbidities might be underestimated and psychiatric 
diagnosis may lack precision, in the absence of a systematic psychiatric assessment. However, all patients underwent the same clinical and neurophysiological assessment and a standardized file review. Severity of recorded symptoms was not assessed. Therefore, severity could not be compared across phenotypes or demographic groups.

\section{Demographic characteristics}

In our series, the majority of patients were women with a median age at the symptoms onset of 35 years old. These demographic characteristics are similar to those of previous series of adults suffering from FMDs, which reported a proportion of women between 48 and $84 \%$, and a mean age at onset between 29.7 and 46.9 years old [4-9,19-21](see supplementary Table 4). It should be noted that extreme ages were under-represented, as discussed earlier. Patients had relatively long disease duration, with a mean duration of 52 months in our series that may be explained by a recruitment bias because Salpêtrière Neurology Department is a tertiary center, especially for movement disorders.

\section{$\underline{\text { Clinical characteristics }}$}

Tremor and dystonia were the most prevalent presentations among movement disorders (83.4\%). This has also been described in previous series of functional movement disorders $[4,5,8,20,21]$

We found no demographic differences between functional weakness and functional movement disorders. Another recent study failed to find differences between groups of functional motor symptoms, regarding demographics and tempo of appearance. The authors concluded that the large overlap in the patients' characteristics support the hypothesis of shared underlying mechanisms of various functional motor disorders. Alternatively, the absence of significant difference might be due to a lack of power, at least for the less frequent phenotypes such as jerks and parkinsonism. Of note, there was a tendency towards an older age at onset in movement disorders, notably in patients with functional parkinsonism (mean: 48.3 years old). In a recent literature review, the mean age at onset in functional parkinsonism was 45.6 years [13]. On the contrary, age at onset was lower in functional dystonia (mean: 35.2 ), and this is also in agreement with a previous study that found age at onset of 29.6 years old in functional dystonia. It is interesting to note that this age difference is similar to what is observed in so-called "organic" diseases, where dystonia affects younger patients than Parkinson's disease. This raises the possibility of a partial overlap in the pathophysiology of 
both functional and organic disorders. It may also be linked to suggestion and interpersonal behavioral priming effects [22].

In our patients, weakness affected more the left side, notably when the lower limbs were affected, whereas movement disorders were more likely to be bilateral. The lateralization of FMD has been a subject of debate [14]. Although this was not the aim of the study, our results raise the question of lateralization of functional weakness. Further studies would be necessary to confirm these results and to determine the pathophysiological explanation to this lateralization.

An acute or subacute onset was reported in $95 \%$ of our patients. Acute onset is often reported in FMD, and was noticed in the majority of patients in previous series of FMDs $[5,8,20,23]$. It is usually considered as a clue for the diagnosis of functional movement disorders [24]. In a previous study, panic and dissociative symptoms has been associated with a sudden onset of FMD, but the reasons of this sudden occurrence is still not clearly elucidated.

\section{Comorbidities:}

In our patients, $18.5 \%$ had a neurological comorbidity, and $66.4 \%$ had a psychiatric comorbidity. These figures were comparable to those described in an Italian series of 410 patients with FMD, where $17 \%$ had a comorbidity of neurological disorder, and $40 \%$ had a psychiatric comorbidity [5]. Of note, a significant proportion of patients had no psychiatric comorbidity or history of trauma, in agreement with the exclusion of psychological factors in the latest diagnostic criteria of FND [25]. However, these results about psychiatric comorbidities should be taken with caution. The proportion of trauma and psychiatric comorbidities might be significantly underestimated, and psychiatric diagnosis may lack precision because of the absence of systematic psychiatric interviews and psychiatric questionnaires in the present study. This may explain the absence of between-groups differences regarding psychiatric comorbidities.

\section{Disability:}

In our study, $77.0 \%$ of patients were not working and $58.3 \%$ were not working because of FND. This data was not available in most previous studies. Unemployment was reported only in three previous series of FMD patients: unemployment rate was $47 \%$ in a study of 66 functional movement disorders patients regardless of the reason of unemployment [21], in a 
study of 107 patients with functional weakness, $65 \%$ of the patients were not working because of their symptoms [9] and in a series of $160 \mathrm{FMD}$ patients, 56\% were not working because of their symptoms [19]. These proportions are higher than in a previous study of neurological outpatients with symptoms 'unexplained by organic disease', where 297 out of 1144 (26\%) patients were not working because of their symptoms [9,26]. More generally, it has been shown that patients with medically unexplained symptoms or somatoform disorders have a higher risk of sick leave and disability pension award during follow-up [27], and the proportion of unemployment in FMD seems comparable to other neurological diseases such as Parkinson's disease [28,29] or cervical dystonia [30]. It has been previously shown that disability and quality of life alteration is as severe in FMD as in other neurological disease [9,31]. Our results point to the huge socio-economical burden of FMD and emphasize the need for better diagnostic procedure and active management.

Future studies are needed to clarify the characteristics of FMD patients and the consequences of their symptoms on disability and work status. Additionally, large international multicentric studies may help to better characterize FMD patients and to assess whether cultural background influence symptom presentation, their consequences and the comorbidities.

\section{References:}

[1] J. Stone, A. Carson, R. Duncan, R. Coleman, R. Roberts, C. Warlow, C. Hibberd, G. Murray, R. Cull, A. Pelosi, J. Cavanagh, K. Matthews, R. Goldbeck, R. Smyth, J. Walker, A.D. Macmahon, M. Sharpe, Symptoms "unexplained by organic disease" in 1144 new neurology out-patients: how often does the diagnosis change at follow-up?, Brain J. Neurol. 132 (2009) 2878-2888. https://doi.org/10.1093/brain/awp220.

[2] V. Voon, C. Brezing, C. Gallea, R. Ameli, K. Roelofs, W.C. LaFrance, M. Hallett, Emotional stimuli and motor conversion disorder, Brain. 133 (2010) 1526-1536. https://doi.org/10.1093/brain/awq054.

[3] L. Ludwig, J.A. Pasman, T. Nicholson, S. Aybek, A.S. David, S. Tuck, R.A. Kanaan, K. Roelofs, A. Carson, J. Stone, Stressful life events and maltreatment in conversion (functional neurological) disorder: systematic review and meta-analysis of case-control studies, Lancet Psychiatry. 5 (2018) 307-320. https://doi.org/10.1016/S2215-0366(18)300518 .

[4] J.F. Baizabal-Carvallo, J. Jankovic, Gender Differences in Functional Movement Disorders, Mov. Disord. Clin. Pract. 7 (2020) 182-187. https://doi.org/10.1002/mdc3.12864.

[5] M. Tinazzi, F. Morgante, E. Marcuzzo, R. Erro, P. Barone, R. Ceravolo, S. Mazzucchi, A. Pilotto, A. Padovani, L.M. Romito, R. Eleopra, M. Zappia, A. Nicoletti, C. Dallocchio, C. Arbasino, F. Bono, A. Pascarella, B. Demartini, O. Gambini, N. Modugno, E. 
Olivola, V. Di Stefano, A. Albanese, G. Ferrazzano, A. Tessitore, M. Zibetti, G. CalandraBuonaura, M. Petracca, M. Esposito, A. Pisani, P. Manganotti, F. Stocchi, M. Coletti Moja, A. Antonini, G. Defazio, C. Geroin, Clinical Correlates of Functional Motor Disorders: An Italian Multicenter Study, Mov. Disord. Clin. Pract. 7 (2020) 920-929. https://doi.org/10.1002/mdc3.13077.

[6] M. Binzer, P.M. Andersen, G. Kullgren, Clinical characteristics of patients with motor disability due to conversion disorder: a prospective control group study, J. Neurol. Neurosurg. Psychiatry. 63 (1997) 83-88.

[7] A. Schrag, M. Trimble, N. Quinn, K. Bhatia, The syndrome of fixed dystonia: an evaluation of 103 patients, Brain J. Neurol. 127 (2004) 2360-2372.

https://doi.org/10.1093/brain/awh262.

[8] S.A. Factor, G.D. Podskalny, E.S. Molho, Psychogenic movement disorders: frequency, clinical profile, and characteristics, J. Neurol. Neurosurg. Psychiatry. 59 (1995) 406-412.

[9] J. Stone, C. Warlow, M. Sharpe, The symptom of functional weakness: a controlled study of 107 patients, Brain J. Neurol. 133 (2010) 1537-1551. https://doi.org/10.1093/brain/awq068.

[10] A. Batla, M. Stamelou, M.J. Edwards, I. Pareés, T.A. Saifee, Z. Fox, K.P. Bhatia, Functional movement disorders are not uncommon in the elderly, Mov. Disord. Off. J. Mov. Disord. Soc. 28 (2013) 540-543. https://doi.org/10.1002/mds.25350.

[11] C.M. de Gusmão, R.M. Guerriero, M.E. Bernson-Leung, D. Pier, P.I. Ibeziako, S. Bujoreanu, K.P. Maski, D.K. Urion, J.L. Waugh, Functional neurological symptom disorders in a pediatric emergency room: diagnostic accuracy, features, and outcome, Pediatr. Neurol. 51 (2014) 233-238. https://doi.org/10.1016/j.pediatrneurol.2014.04.009.

[12] S.M.A. van der Salm, R. Erro, C. Cordivari, M.J. Edwards, J.H.T.M. Koelman, T. van den Ende, K.P. Bhatia, A.-F. van Rootselaar, P. Brown, M.A.J. Tijssen, Propriospinal myoclonus: clinical reappraisal and review of literature, Neurology. 83 (2014) 1862-1870. https://doi.org/10.1212/WNL.0000000000000982.

[13] M. Ambar Akkaoui, P. Geoffroy, E. Roze, B. Degos, B. Garcin, Functional Motor Symptoms in Parkinson's Disease and Functional Parkinsonism: A Systematic Review, J. Neuropsychiatry Clin. Neurosci. (2020). https://doi.org/10.1176/appi.neuropsych.19030058.

[14] J. Stone, M. Sharpe, A. Carson, S.C. Lewis, B. Thomas, R. Goldbeck, C.P. Warlow, Are functional motor and sensory symptoms really more frequent on the left? A systematic review, J. Neurol. Neurosurg. Psychiatry. 73 (2002) 578-581.

https://doi.org/10.1136/jnnp.73.5.578.

[15] R.M. van der Hoeven, M. Broersma, G.H.M. Pijnenborg, E.A. Koops, T. van Laar, J. Stone, M. van Beilen, Functional (psychogenic) movement disorders associated with normal scores in psychological questionnaires: A case control study, J. Psychosom. Res. 79 (2015) 190-194. https://doi.org/10.1016/j.jpsychores.2015.06.002.

[16] S. Kranick, V. Ekanayake, V. Martinez, R. Ameli, M. Hallett, V. Voon, Psychopathology and psychogenic movement disorders, Mov. Disord. Off. J. Mov. Disord. 
Soc. 26 (2011) 1844-1850. https://doi.org/10.1002/mds.23830.

[17] B. Garcin, E. Roze, F. Mesrati, E. Cognat, E. Fournier, M. Vidailhet, B. Degos, Transcranial magnetic stimulation as an efficient treatment for psychogenic movement disorders, J. Neurol. Neurosurg. Psychiatry. 84 (2013) 1043-1046.

https://doi.org/10.1136/jnnp-2012-304062.

[18] A. Gupta, A.E. Lang, Psychogenic movement disorders, Curr. Opin. Neurol. 22 (2009) 430-436. https://doi.org/10.1097/WCO.0b013e32832dc169.

[19] J.M. Gelauff, J.G.M. Rosmalen, J. Gardien, J. Stone, M. a. J. Tijssen, Shared demographics and comorbidities in different functional motor disorders, Parkinsonism Relat. Disord. 70 (2020) 1-6. https://doi.org/10.1016/j.parkreldis.2019.11.018.

[20] S. Pandey, A. Koul, Psychogenic Movement Disorders in Adults and Children: A Clinical and Video Profile of 58 Indian Patients, Mov. Disord. Clin. Pract. 4 (2017) 763-767. https://doi.org/10.1002/mdc3.12516.

[21] K.E. Anderson, A.L. Gruber-Baldini, C.G. Vaughan, S.G. Reich, P.S. Fishman, W.J. Weiner, L.M. Shulman, Impact of psychogenic movement disorders versus Parkinson's on disability, quality of life, and psychopathology, Mov. Disord. Off. J. Mov. Disord. Soc. 22 (2007) 2204-2209. https://doi.org/10.1002/mds.21687.

[22] J.A. Bargh, M. Chen, L. Burrows, Automaticity of social behavior: direct effects of trait construct and stereotype-activation on action, J. Pers. Soc. Psychol. 71 (1996) 230-244. https://doi.org/10.1037//0022-3514.71.2.230.

[23] J. Stone, C. Warlow, M. Sharpe, Functional weakness: clues to mechanism from the nature of onset, J. Neurol. Neurosurg. Psychiatry. 83 (2012) 67-69.

https://doi.org/10.1136/jnnp-2011-300125.

[24] A.J. Espay, S. Aybek, A. Carson, M.J. Edwards, L.H. Goldstein, M. Hallett, K.

LaFaver, W.C. LaFrance, A.E. Lang, T. Nicholson, G. Nielsen, M. Reuber, V. Voon, J. Stone, F. Morgante, Current Concepts in Diagnosis and Treatment of Functional Neurological

Disorders, JAMA Neurol. 75 (2018) 1132-1141.

https://doi.org/10.1001/jamaneurol.2018.1264.

[25] J. Stone, W.C. LaFrance, R. Brown, D. Spiegel, J.L. Levenson, M. Sharpe, Conversion disorder: current problems and potential solutions for DSM-5, J. Psychosom. Res. 71 (2011) 369-376. https://doi.org/10.1016/j.jpsychores.2011.07.005.

[26] A. Carson, J. Stone, C. Hibberd, G. Murray, R. Duncan, R. Coleman, C. Warlow, R. Roberts, A. Pelosi, J. Cavanagh, K. Matthews, R. Goldbeck, C. Hansen, M. Sharpe, Disability, distress and unemployment in neurology outpatients with symptoms "unexplained by organic disease," J. Neurol. Neurosurg. Psychiatry. 82 (2011) 810-813. https://doi.org/10.1136/jnnp.2010.220640.

[27] M.T. Rask, M. Rosendal, M. Fenger-Grøn, F. Bro, E. Ørnbøl, P. Fink, Sick leave and work disability in primary care patients with recent-onset multiple medically unexplained symptoms and persistent somatoform disorders: a 10-year follow-up of the FIP study, Gen. Hosp. Psychiatry. 37 (2015) 53-59. https://doi.org/10.1016/j.genhosppsych.2014.10.007. 
[28] R. Murphy, N. Tubridy, H. Kevelighan, S. O'Riordan, Parkinson's disease: how is employment affected?, Ir. J. Med. Sci. 182 (2013) 415-419. https://doi.org/10.1007/s11845013-0902-5.

[29] J. Koerts, M. König, L. Tucha, O. Tucha, Working capacity of patients with Parkinson's disease - A systematic review, Parkinsonism Relat. Disord. 27 (2016) 9-24. https://doi.org/10.1016/j.parkreldis.2016.03.017.

[30] K.K. Martikainen, T.H. Luukkaala, R.J. Marttila, Working capacity and cervical dystonia, Parkinsonism Relat. Disord. 16 (2010) 215-217.

https://doi.org/10.1016/j.parkreldis.2009.07.006.

[31] T. Gendre, G. Carle, F. Mesrati, C. Hubsch, T. Mauras, E. Roze, M. Houot, B. Degos, B. Garcin, Quality of life in functional movement disorders is as altered as in organic movement disorders, J. Psychosom. Res. 116 (2019).

https://doi.org/10.1016/j.jpsychores.2018.11.006. 
Table 1. Demographics, clinical characteristics and medical history of patients with functional motor disorders.

\begin{tabular}{|c|c|c|c|}
\hline \multicolumn{3}{|c|}{ Total number of patients } & 482 \\
\hline \multicolumn{3}{|c|}{ Age at onset in years (Mean (SD)/Median [range]) } & $35.4(14.9) / 35.6[3-75]$ \\
\hline \multicolumn{3}{|c|}{ Age at TMS in years (Mean (SD)/Median [range]) } & $39.7(15.1) / 400[8-77]$ \\
\hline \multicolumn{3}{|c|}{ Symptoms Duration in months (Mean (SD)/Median [range]) } & $52.0(82.5) / 23.9[0-786]$ \\
\hline Gender $(\%(N))$ & \multicolumn{2}{|l|}{ Female } & $73.7 \%(355)$ \\
\hline Education level & \multicolumn{2}{|l|}{$\geq 12$ years } & $55.4 \%(267)$ \\
\hline \multirow{3}{*}{ Occupation } & \multicolumn{2}{|c|}{ Active (employement or study) } & $23.0 \%(111)$ \\
\hline & \multicolumn{2}{|c|}{ Unemployed for medical reasons (FMD) } & $58.3 \%(281)$ \\
\hline & \multicolumn{2}{|c|}{ Unemployed for non-medical reasons } & $18.7 \%(90)$ \\
\hline \multirow{3}{*}{ Symptoms Onset } & \multicolumn{2}{|l|}{ Sudden } & $47.3 \%(228)$ \\
\hline & \multicolumn{2}{|l|}{ Subacute $(<3$ months $)$} & $46.1 \%(222)$ \\
\hline & \multicolumn{2}{|l|}{ Chronic (> 3 months) } & $6.6 \%(32)$ \\
\hline \multirow{7}{*}{$\begin{array}{c}\text { Symptoms } \\
\text { Phenomenology }\end{array}$} & \multicolumn{2}{|l|}{ Motor Weakness } & $50.0 \%(241)$ \\
\hline & \multirow{6}{*}{ Movement Disorders } & Tremor & $42.3 \%(102)$ \\
\hline & & Dystonia & $41.1 \%(99)$ \\
\hline & & Jerky dystonia & $9.1 \%(22)$ \\
\hline & & Parkinsonism & $3.7 \%(9)$ \\
\hline & & Stereotypies & $3.7 \%(9)$ \\
\hline & & Total & $50.0 \%(241)$ \\
\hline \multirow{8}{*}{$\begin{array}{c}\text { Medical Somatic } \\
\text { History }\end{array}$} & \multicolumn{2}{|l|}{ Neurology } & $18.5 \%(89)$ \\
\hline & \multicolumn{2}{|c|}{ Orthopaedics/Rheumatology/Algodystrophy/Fibromyalgia } & $24.7 \%(119)$ \\
\hline & \multicolumn{2}{|l|}{ Abdominal/Pelvic } & $13.3 \%(64)$ \\
\hline & \multicolumn{2}{|c|}{ Ophthalmology/Otolaryngology } & $3.9 \%(19)$ \\
\hline & \multicolumn{2}{|l|}{ Pneumology } & $0.4 \%(2)$ \\
\hline & \multicolumn{2}{|c|}{ Dermatology/Infectious diseases } & $3.3 \%(16)$ \\
\hline & \multicolumn{2}{|c|}{ Unexplained Loss of Consciousness } & $1.0 \%(5)$ \\
\hline & \multicolumn{2}{|l|}{ None } & $47.3 \%(228)$ \\
\hline \multirow{5}{*}{$\begin{array}{c}\text { Psychiatric } \\
\text { Comorbidities }\end{array}$} & \multirow{3}{*}{ Mood disorders } & Depression & $49.4 \%(238)$ \\
\hline & & Bipolar disorder & $3.3 \%(16)$ \\
\hline & & Total & $52.7 \%(254)$ \\
\hline & \multicolumn{2}{|l|}{ Anxiety disorders } & $7.9 \%(38)$ \\
\hline & \multicolumn{2}{|l|}{ Eating disorders } & $5.2 \%(25)$ \\
\hline
\end{tabular}




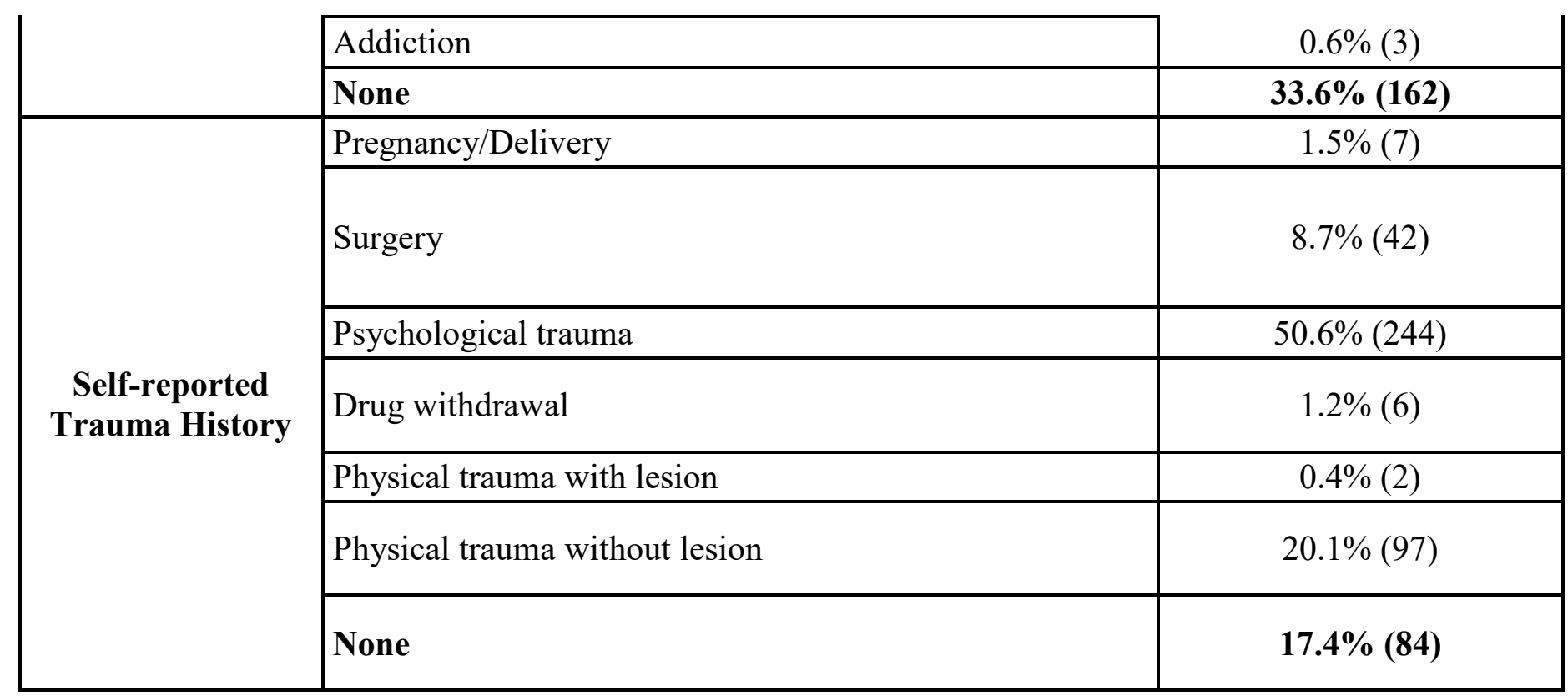

Table 2. Demographics and clinical characteristics of patients according to the functional motor disorder phenotype.

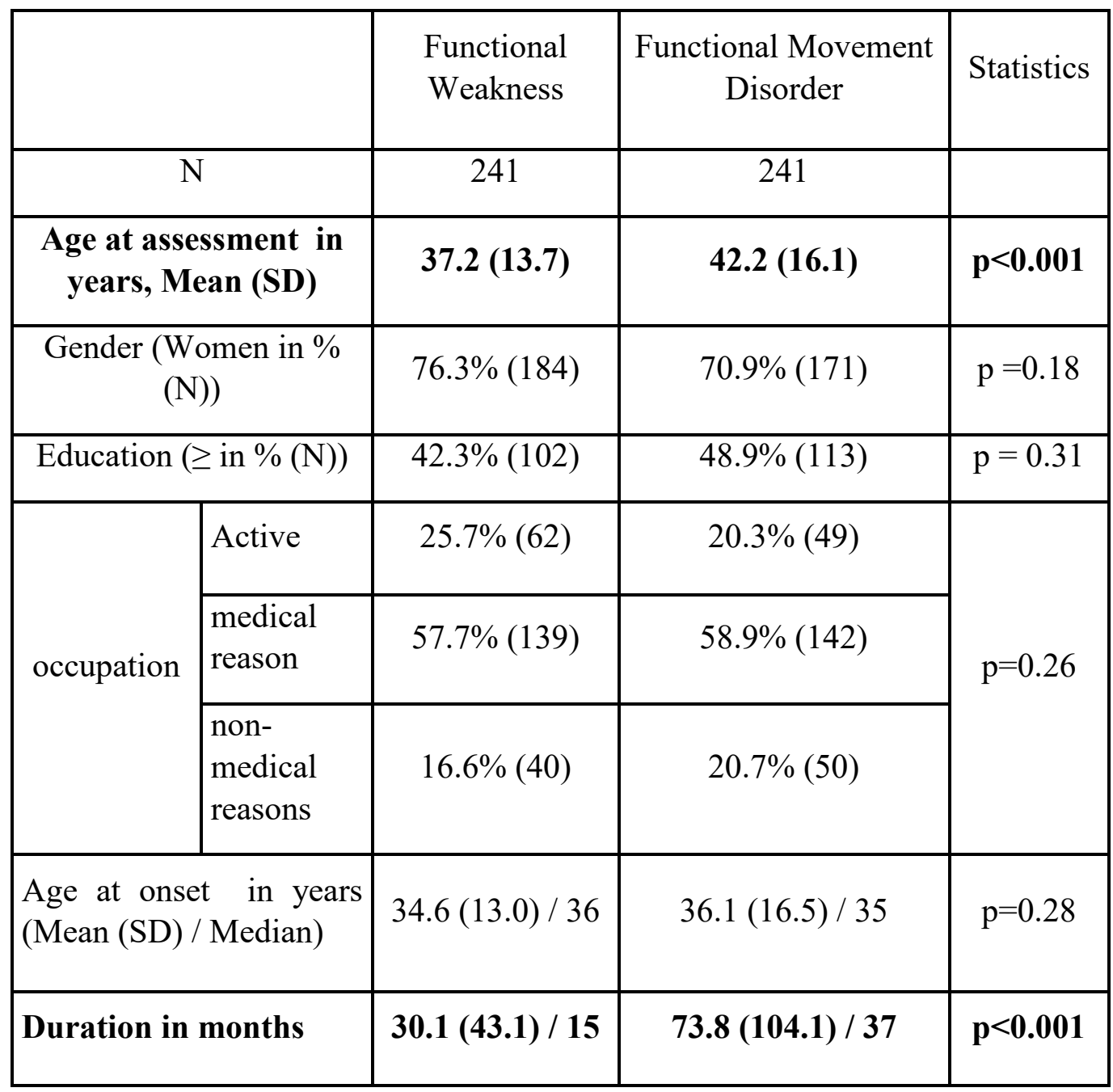




\begin{tabular}{|l|l|c|c|c|}
\hline \multicolumn{2}{|l|}{ (Mean (SD)/Median) } & & \\
\hline \multirow{3}{*}{ Onset } & Acute & $50.2 \%(121)$ & $44.4 \%(107)$ & \\
\cline { 2 - 4 } & Subacute & $44.8 \%(108)$ & $47.3 \%(114)$ & \multirow{2}{*}{$\mathrm{P}=0.22$} \\
\cline { 2 - 4 } & Chronic & $5.0 \%(12)$ & $8.3 \%(20)$ & \\
\hline
\end{tabular}


Table 3. Location of symptoms according to the FMD phenotype.

\begin{tabular}{|l|l|l|l|}
\hline & $\begin{array}{l}\text { Movement } \\
\text { disorders(n(\%)) }\end{array}$ & weakness (n(\%)) & Statistics \\
\cline { 1 - 3 } Bilateral (N(\%)) & $133(55.2)$ & $116(48.1)$ & \multirow{2}{*}{$\chi^{2}=9.52 ; \mathrm{p}=0.009$} \\
\cline { 1 - 3 } Right (N(\%)) & $55(22.8)$ & $42(17.4)$ & \\
\cline { 1 - 3 } Left (N(\%)) & $53(22.0)$ & $83(34.4)$ & \\
\cline { 1 - 3 } Total (N(\%)) & $\mathbf{2 4 1 ( 1 0 0 )}$ & $\mathbf{2 4 1 ( 1 0 0 )}$ & \\
\cline { 1 - 2 } & & &
\end{tabular}

